Review

\title{
Current Assessment of Clinical Pancreatic Islet Allotransplantation
}

Preeti Chhabra ${ }^{\dagger}$, Kenneth L. Brayman ${ }^{\dagger}, *$

Department of Surgery, Transplantation Division, University of Virginia, Charlottesville, VA, USA; EMails: pc6n@hscmail.mcc.virginia.edu; klb9r@hscmail.mcc.virginia.edu

† These authors contributed equally to this work.

* Correspondence: Kenneth L. Brayman; E-Mail: klb9r@hscmail.mcc.virginia.edu

Academic Editors: Kenneth L. Brayman and Preeti Chhabra

Special Issue: Islet Cell Transplantation

OBM Transplantation

2020, volume 4, issue 4

doi:10.21926/obm.transplant.2004125
Received: September 20, 2020

Accepted: November 4, 2020

Published: Novemeber 16, 2020

\begin{abstract}
Clinical islet allotransplantation represents a minimally invasive, efficacious alternative to pancreas transplantation for restoring glycemic control and insulin independence in select patients with type 1 diabetes that is complicated by intractable impaired hypoglycemia awareness and/or severe hypoglycemic events refractory to stabilization by other means. Over the last decade, islet transplantation outcomes have steadily improved in part due to refinements in the selection of optimal donors, islet isolation techniques, safer engraftment methods, and effective immunomodulatory and anti-inflammatory therapies. Insulin independence rates at five years post-transplantation at select centers have reached parity with pancreas alone transplantation, and marked progress has been achieved in islet transplantation outcomes using single-donor pancreas. However, widespread application of the procedure is still hindered due to a limited supply of donor pancreases, inadequate engraftment, and the harmful side effects of chronic immunosuppression. Strategies to address some of these challenges involve the use of alternative sources of beta cells or islets, extrahepatic sites of implantation, encapsulation of islets and novel therapies to induce tolerance. While several countries have now transitioned islet transplantation from
\end{abstract}

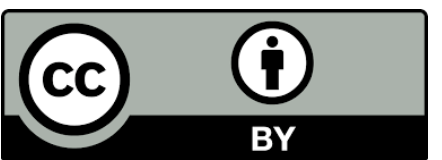

(C) 2020 by the author. This is an open access article distributed under the conditions of the Creative Commons by Attribution License, which permits unrestricted use, distribution, and reproduction in any medium or format, provided the original work is correctly cited. 
experimental status to a funded clinical cure for patients with brittle type 1 diabetes that cannot be stabilized by more conventional means, in the US it still awaits regulatory approval and a financial mechanism for sustainable reimbursement. This review details the history and the current status of clinical islet allotransplantation while summarizing improvements that have been made in techniques involving isolation, purification, culture and assessment of human islets as well as the islet transplantation process itself. Furthermore, it discusses the limitations encountered that prevent its widespread application, strategies that address those limitations, and last but not least, clinical trials being conducted that will help position islet transplantation as a mainstay treatment for the cure of type 1 diabetes.

\section{Keywords}

The collaborative islet transplant registry; islet isolation; intra-hepatic portal vein clinical islet transplantation; allosensitization; shortage of donor pancreata; immunosuppression; graft function; islet/beta cell encapsulation strategies; islet transplantation in extrahepatic sites

\section{Introduction}

Pancreas or islet transplantation is currently the only known cure for Type 1 Diabetes (T1D) [1, 2], a chronic, progressive autoimmune disease that affects an estimated 1.25 million American children and adults $[3,4]$. Classic symptoms of the disease include polydipsia, polyuria, and polyphagia, while diagnosis is usually confirmed by hyperglycemia, low or undetectable serum Cpeptide levels, elevated glycosylated hemoglobin $(\mathrm{HbA} 1 \mathrm{c})$, and the presence of one or more positive autoantibody markers [5]. The current treatment for T1D consists of intensive diet management coupled with exogenous insulin therapy $[6,7]$. Multiple daily injections of insulin, continuous glucose monitoring systems and insulin pumps, or an artificial pancreas device such as Medtronic's MiniMed 670G system constitute the latter [7-10]. Although the tightened glycemic control resulting from insulin therapy has proved highly successful in reducing secondary complications, unfortunately the treatment often renders patients susceptible to increased risk of hypoglycemic episodes and unawareness [11]. To date, allotransplantation of beta cells remains the most reliable and consistent approach for curing T1D.

Pancreatic islet transplantation is a beta cell replacement strategy for clinically restoring glycometabolic control in type 1 diabetic patients that suffer from complications of recalcitrant glycemic lability or debilitating incidences of hypoglycemic episodes and unawareness [12-14]. The procedure first gained credibility as a viable cure in the year 2000, when Shapiro et al demonstrated that transplantation of an adequate mass of islets combined with glucocorticoidfree immunosuppression could result in insulin independence with excellent metabolic control [15]. Since then, incremental advances in a number of parallel fields such as donor selection, islet product quality, anti-rejection/anti-inflammatory agents and state-of-art technology helped evolve islet transplantation into an efficacious clinical means for routinely achieving normoglycemia. Currently, select centers (University of Minnesota (UMN), University of Alberta, 
Edmonton (UAlberta), University of Geneva (UNIGE), University of Lille (ULille) and University of California San Francisco (UCSF)) have demonstrated achievement of insulin independence in nearly $50 \%$ of recipients at the five years post-transplantation mark using T-cell depletional induction therapies, bringing it on par with the results observed with whole pancreas transplantation [14, 16-22]. The procedure also offers substantial benefits when compared to pancreatic transplantation, being minimally invasive while improving the patient's overall metabolic homeostasis as well as quality of life. However, despite the significant progress that has been made in this field during the past decade, it is still not considered as a mainstream treatment option for patients with T1D. Factors such as the requirement of multiple donors, graft rejection, the recurrence of autoimmunity, the harmful side-effects of chronic diabetogenic and nephrotoxic immunosuppression, as well as financial and regulatory approval issues still need to be overcome in order to allow its inclusion into the clinical repertoire as a cure for T1D. This review explores the current status of islet transplantation and the steps that are being taken to expand the availability of this procedure as a fundable clinical option for curing T1D.

\subsection{Historical Perspective of Islet Transplantation}

The use of insulin as a treatment for T1D was first reported in 1922 by Banting and colleagues [23]. However, the theory that pancreatic extracts contained a vital substance that could relieve diabetic symptoms had already been a topic of debate before this report. As early as in 1892, von Merring and Minkowski demonstrated that mortality associated with total pancreactomy could be prevented by subcutaneous transplantation of autologous pancreatic fragments into a diabetic canine recipient [24]. Soon after in 1894, Watson-Williams and Harsant transplanted fragments of sheep pancreas into a teenage boy with end-stage diabetes and demonstrated temporary improvement in glycosuria [25]. In 1916, Frederick Charles Pybus transplanted human allogeneic cadaveric pancreatic fragments subcutaneously into two diabetic patients with no success [26].

The concept of physically separating exocrine and endocrine pancreas had first been contemplated by Leonid Ssobolew [27] as early as in 1902, and continued to gain momentum in the years that followed as numerous techniques to isolate islets were investigated. Moskalewsky was the first to use a discontinuous gradient to purify pig pancreatic islets with Ficoll in 1965 [28]; and the technique was subsequently perfected in Paul Lacy's laboratory [29]. They used a novel technique to isolate rat islets that involved distending the pancreas with saline followed by enzymatic digestion. Ground-breaking experiments by Ballinger and Lacy in rodents followed in the period 1972-1973 that demonstrated reversal of chemically induced diabetes in rats by intact islet transplantation [30]. These early preclinical studies paved the way for using the technique as a potential clinical treatment option for T1D. The same team also demonstrated the vital impact of the site of transplantation on transplantation outcomes, demonstrating islet embolization into the liver through the portal vein, a clinically relevant site that still remains the preferred site for islet transplantation [31]. Between 1979 to 1980, Sutherland and Najarian performed both autologous and allogeneic islet transplantations using dispersed pancreatic islet microfragments following pancreactomy [32-34]. They performed intraportal islet transplantations in 10 patients with surgical induced diabetes using islet autografts that were infused back following islet isolation. Three of these patients achieved insulin independence for 1, 9 and 38 months respectively. 
While working in Paul Lacy's laboratory, Camillo Ricordi and colleagues developed the Ricordi ${ }^{\circledR}$ Chamber and perfected the semi-automated method for islet isolation that enabled successful harvesting of sufficient numbers of human islets for transplantation [35, 36]. Briefly, the Ricordi ${ }^{\circledR}$ Chamber consisted of lower and upper stainless steel chambers separated by a stainless steel screen (280 um mesh). The lower cylindrical chamber had two inlet ports and a third opening on the side for a temperature probe. The upper chamber was conical with one output opening. Both chambers were held together by three screws and the device was connected to a shaker (Model 75, Burrel, Pittsburgh, PA) by a stainless steel bar. Enzyme infused pancreas was loaded into the lower chamber along with seven glass marbles. The chamber was filled with additional collagenase solution, the screen placed in position and the device closed. The shaker was then activated (320 oscillations/minute) and the peristaltic pump turned on with a flow rate of $40 \mathrm{~mL} / \mathrm{min}$. Digestion of the pancreas was conducted in a closed system in which Hanks' solution was aspirated through a filter (94 um mesh) placed in the upper portion of the recirculation cylinder, passed through the pump to a heating circuit and finally reached the lower chamber of the isolator progressively diluting the collagenase solution inside the chamber. The heating circuit allowed the temperature in the digestion chamber to progressively increase $\left(1{ }^{\circ} \mathrm{C} / \mathrm{min}\right)$ until $37^{\circ} \mathrm{C}$ was reached, following which a heating circuit bypass was switched on and off to maintain a stable temperature. From the lower chamber, the solution then passed through the 280 um screen to a cooling circuit that inactivated the collagenase and finally returned to the lower portion of the recirculation cylinder. Both the cooling circuit and the recirculation cylinder were placed in an ice bath in order to inactivate the collagenase and preserve the islets. The solution was then drawn from the top of the recirculation cylinder through the 94um filter while the islets remain settled at the bottom of the cylinder. The islet preparation was sampled every two minutes from a stopcock near the output opening of the digestion chamber to monitor the digestion. When free islets were detected, the recirculation cylinder and the heating circuit were bypassed and the islet separation conducted on an open system in which the temperature progressively decreased, and the collagenase solution was diluted by fresh Hanks' solution. The islet preparation was then collected in 2-Liter flasks. The flow rate in the open system phase increased up to $200 \mathrm{~mL} / \mathrm{min}$, allowing a faster turnover of the digestion chamber content. The isolation procedure was generally terminated after 30-60 min, when islets were no longer detected in the samples [35].

By 1990, the first successful series of clinical human islet allotransplantation was reported by the Pittsburgh group wherein long-term insulin independence could be attained using a steroidfree immunosuppressive regimen that included FK506 (Prograf) [37, 38]. These exciting results invigorated efforts in the field. During that decade, several centers including those at University of Miami (UM), UAlberta, Washington University, University of Pennsylvania (UPenn), UMN, and San Raffaele University, Milan (UniSR) incorporated innovative changes to existing protocols to improve islet transplantation outcomes [39-41]. However it was in the year 2000 that the islet transplantation group consisting of Shapiro and colleagues at UAlberta demonstrated achievement of insulin independence for $>1$ year post-transplantation with sustained C-peptide production in all seven consecutive participants who had received islets transplants, using what is now famously known as the "Edmonton protocol" [15]. The protocol briefly consisted of a corticosteroid free immunosuppressive protocol consisting of a combination of two potent immunosuppressants: rapamycin and low-dose tacrolimus, together with an anti-CD25 antibody to protect against rejection and recurrent autoimmunity. Using this protocol, the islet mass was 
augmented with islet preparations harvested from two or more pancreata, infusing a total islet dose substantially higher than previously used in clinical islet trials ( $>13,000$ islet equivalents (IEQs) per kilogram $(\mathrm{kg})$ recipient body weight) [42]. Although the Edmonton protocol consistently achieved short-term outcomes on par with pancreas transplantation at 1 year follow-up, insulin independence was frequently lost in the graft recipients by the 3-5 year mark, with only $10 \%$ demonstrating insulin independence at the five year mark [43]. However, partial graft function (defined as partial insulin dependence) consistently persisted in $80 \%$ of graft recipients contributing to decreased episodes of severe hypoglycemia, reduced $\mathrm{HbA} 1 \mathrm{c}$ levels, and improved cardiovascular function [44]. Furthermore, stabilization of diabetic retinopathy and neuropathy was observed, resulting in improved quality of life with increased glycemic awareness. From 20062012, a spate of activity ensued with several centers worldwide and as well as independent Clinical Islet Transplantation (CIT) centers (for example, UAlberta, UMN, UCSF, Geneva-GRAGIL, and ULille) reporting insulin-independence rates of more than $50 \%$ at five years using T-cell depletion induction therapies [21, 22, 45-50]. Importantly, their results closely approximated the International Pancreas Transplant Registry data of solitary vascularized pancreas transplant [21, 22, 51-54]. Noteworthy was that these results demonstrated that the procedure was not associated with the incumbent risks that attend a major surgical intervention like pancreas transplantation $[21,22,54]$.

\subsection{The Collaborative Islet Transplant Registry}

The Collaborative Islet Transplant Registry (CITR) was established in 2001 by the National Institute of Diabetes \& Digestive \& Kidney Diseases to compile data from all islet transplant programs in North America from 1999 to the present. Additional funding was granted by the Juvenile Diabetes Research Foundation (JDRF) to include JDRF-funded European and Australian centers from 2006-2015. The cumulated data from North American, European and Australian centers are pooled for analyses and are included in the annual reports.

Briefly, data is collected from the following groups of study subjects: A) Islet allotransplantation performed as either islet transplant alone or islet after kidney (IAK) [55]. A small number of cases have been performed as islet simultaneous with kidney or kidney-after-islet; and B) Autologous islet transplantation, performed after total pancreatectomy. The CITR 10th Annual Report focuses on the islet allotransplantation recipients. It states that 1086 islet allotransplant recipients (877 islet alone, 183 islet after kidney, 24 simultaneous islet kidney, and 2 kidney after islet) have received 2,150 islet allograft infusions, representing a $7 \%$ increase in the number of recipients, a $12 \%$ increase in the number of infusion procedures, and $8 \%$ increase in donors, compared to the 9th Report during the period from 1999 to 2015. Also, a total of 827 autologous islet transplant recipients were registered in CITR, as of Sept 30, 2015. In North America 33 out of 42 programs have performed islet allograft transplantations with 669 total recipients and 1,321 total infusions.

\section{The Islet Transplantation Process}

\subsection{Indications for Clinical Islet Transplantation}

The main indication for an allogeneic islet transplant is undetectable C-peptide levels $(<0.3 \mathrm{ng} / \mathrm{mL})$ with severe glycemic lability complicated with recurrent hypoglycemic episodes and 
impaired hypoglycemic awareness [2,39]. Also included are patients refractory to efforts aimed at stabilizing glycometabolic control such as intensive insulin therapy, improved monitoring, insulin pumps, or continuous glucose monitoring systems. Evidence of T1D (C-peptide $<0.3 \mathrm{ng} / \mathrm{mL}$ ) with sufficient duration ( $>5$ years) is required to justify that adequate opportunity for optimized medical management has been provided. Age is restricted to $>18$ years, and subjects $>90 \mathrm{~kg}$ and/or with daily insulin requirement $>1.0 \mathrm{U} / \mathrm{kg}$ and/or with a high body mass index $\left(\mathrm{BMI}>30 \mathrm{~kg} / \mathrm{m}^{2}\right)$ are usually avoided to prevent the futility of transplantation in the presence of marked insulin resistance or excessively high insulin requirements [14].

Stringent selection criteria have been put in place to justify replacing injectable insulin with lifelong immunosuppression. Usually an objective selection criteria for islet transplantation alone include a Clark score of $\geq 4$ ( $0=$ no hypoglycemia, $\geq 4$ = hypoglycemia unawareness), HYPO score $\geq 1000$; lability index (LI) score $\geq 400 \mathrm{mmol} / \mathrm{L} 2 / \mathrm{h} / \mathrm{wk}$, or a combination of these variables $[2,21,51]$. Patients having subcutaneous insulin resistance requiring intraperitoneal or intravenous infusions are also considered. Also included are patients that do not qualify as candidates for wholepancreas transplantation or are unable to accept the risks associated with major surgery.

According to latest CITR annual report [55], at the time of their first Islet transplant, islet transplant alone recipients were 14-74 years of age (mean 46 \pm 10.5 years), had T1D for 2-61 years (mean $29 \pm 11.5$ years), and $77 \%$ had very poor diabetes control including hypoglycemia unawareness. Poor glycemic control was defined as frequent episodes of critically low blood sugar levels (which often result as a reaction to injected insulin, and require the assistance of another person to avert a possibly life-threatening loss of consciousness), wide swings in blood sugar levels (blood glucose lability), or consistently high HbA1c levels (>8\% of total hemoglobin). Typically, those selected displayed frequent metabolic instability involving hypo-and hyperglycemia, ketoacidosis despite intensive insulin therapy; hypoglycemic unawareness $(<54 \mathrm{mg} / \mathrm{dL})$; and severe metabolic lability (mean amplitude of glycemic excursion $>11.1 \mathrm{mmol} / \mathrm{L}$ or $200 \mathrm{mg} / \mathrm{dL}$ ).

There is less agreement on the exclusion criteria, however absolute contraindications is detectable C-peptide levels $(>0.3 \mathrm{ng} / \mathrm{mL})$. Relative contraindications include insulin requirements (>0.7units $/ \mathrm{kg} /$ day) or $<15$ units/day, $\mathrm{HbA} 1 \mathrm{c}>10 \%$, BMI $>26 \mathrm{~kg} / \mathrm{m}^{2}$ or weight $<50 \mathrm{~kg}$, Creatinine $>1.5 \mathrm{mg} / \mathrm{dL}$ and/or albuminuria $>300 \mathrm{mg} / 24 \mathrm{~h}$ or measured glomerular filtration rate (GFR) $<80 \mathrm{~mL} / \mathrm{min} / 1.73 \mathrm{~m}^{2}$, untreated arterial disease, history of panel reactive anti-human leukocyte antigen (HLA) antibodies, inability to comply with immunosuppression and significant comorbidities, as well as the presence of infections or psychiatric diseases $[14,56,57]$.

\subsection{Islet Isolation}

The islet transplantation process begins with procurement of the pancreas, usually from a heart-beating, brain-dead organ donor or in the case of autologous islet transplantation, from a recipient undergoing therapeutic pancreactomy [2]. The pancreas is transported in University of Wisconsin (UW) or histidine-tryptophan-ketoglutarate (HTK) preservation solution to a sterile good manufacturing practice (GMP) facility, avoiding prolonged cold storage of the pancreas [12]. Multiple reports indicate that other preservation solutions may be used as effective alternatives to UWS and HTK $[58,59]$. For example, Celsior is an extracellular, low-viscosity preservation solution that was originally designed for cardiac transplantation. A study comparing Celsior with UWS for pancreas preservation demonstrated that two-year recipient survival rates, two-year graft survival 
rates, pancreas leakage rates, and clinical graft pancreatitis rates were similar in both groups [58]. However, colloid-free preservation solutions were reported to be inferior to UWS for preservation of pancreases intended to be used for islet isolation. Islet isolation yields from pancreases preserved with Celsior solution were found to be 2.1-fold lower than those obtained when UWS was used $[59,60]$. Solution de conservation d'organes et de tissus (SCOT), an extracellular solution containing polyethylene glycol (PEG) has been shown to have some immunoprotective effects on islet cells [61]. Cell swelling and pancreas edema were not significant following 12 hours of cold storage with SCOT when compared with UWS, and SCOT could improve islet yield when used during isolation and could prolong islet allograft survival without immunosuppression when used for culture, as compared to control solutions $[59,61]$. Perfluorohexyloctane/Polydimethylsiloxane 5 (F6H8S5) too has been demonstrated to be a suitable preservation solution for pancreases intended for islet isolation, allowing for extended cold ischemic time without inflicting islet function and numbers [62]. A technique known as the two-layer method (TLM) for pancreas preservation was reported to enhance islet yield and quality by improving pancreas oxygenation during preservation [62]. Following reports in 2002 by UMN [63], UM [64], and UAlberta [65, 66] that indicated improved islet yields and increased islet transplantation opportunities using TLM, this technique was widely used by islet transplant centers worldwide. However, several clinical studies since have demonstrated no beneficial effect of the TLM with preoxygenated perfluorocarbon on islet isolation and islet transplant outcomes [67-69].

Once received, the pancreas is cleaned and cannulated and infused with enzyme in the GMP facility. The distended pancreas is cut into seven to ten pieces and subjected to continuous, temperature controlled, mechanically enhanced enzymatic digestion in a dissociation or filtration chamber known as the Ricordi ${ }^{\circledR}$ Chamber that allows immediate cooling and removal of the dissociated islets to avoid overdigestion, thus preserving their morphologic and functional islet integrity [2]. Liberase $\mathrm{H} 1$ was the commonly used enzyme until the discovery of potential safety risks regarding the contraction of bovine spongiform encephalopathy $[2,12,70]$. Consequently, collagenase NB1 supplemented with neutral protease (NP) (SERVA Electrophoresis GmbH, Heidelberg, Germany) was adopted by many centers globally as an alternative despite its lower islet isolation outcomes $[2,12,70,71]$. The latter was attributed to degradation of collagenase C1 into various breakdown products with reduced activity [72]. The combination of Clzyme collagenase HA (containing nondegradable class I [60\%] and II [40\%]) and NP although effective in isolating islets for transplantation, however were not GMP grade products [73]. Currently, liberase mammalian tissue-free collagenase/ thermolysin (MTF C/T) (Roche Diagnostics) is being used routinely for human islet isolation for clinical islet transplantation [73].

Pooled tissue containing islets are purified on a Ficoll, Biocoll, lodixanol, or UW-Biocoll density gradient in a COBE2991 processor (Terumo BCT, Gambro BCT, Inc., Lakewood, CO) under cold conditions, which separates them from exocrine and other non-islet tissue $[2,12,14,21]$. The purified islets are washed, pelleted and resuspended, following which an aliquot is removed to quantify islet yield (dithizone-stained islets), evaluate islet size and perform islet count (using light microscopy), assess viability (fluorescein diacetate-propidium iodide staining), sterility and pyrogenicity (endotoxin assay, gram stain and tests for aerobic and anaerobic microbial, fungal, and mycoplasmal contamination), purity (visual morphometric examination of dithizone-stained acinar-free islets using light microscopy) and function (perifusion, glucose-stimulated insulin 
secretion assay) [2]. Within 24 hours of isolation, the resuspended islets are loaded into a gravityfed transfer bag for intraportal vein infusion into the eligible transplant recipient [2].

A healthy human pancreas contains up to 4-15 million islets [57, 74]. However, the yield and purity of isolated purified islets are highly variable with islet equivalents count ranging from 100,000 to 300,000 per pancreas $[57,75]$. The isolated islets are then infused into the hepatic portal system of the recipient. A target islet mass of approximately 11,000 islet IEQs per $\mathrm{kg}$ of recipient body weight is aimed for, translating into two or three islet infusions from multiple donors [21]. However the minimum requirements include $>30 \%$ purity of the preparation being islets, membrane integrity-viability $\geq 70 \%$, a final enriched islet cell product in $<5 \mathrm{~cm}^{3}$ of tissue pellet, negative Gram stain, content $\leq 5$ endotoxin $\mathrm{U} / \mathrm{kg}$ (recipient body weight) and most importantly, adequate number of islets i.e. $\geq 5,000$ islet equivalent recipient body weight for the first infusion and $\geq 3,000$ for further infusions [76-79]. According to the latest CITR annual report [55], the total cell volume infused has declined appreciably over the eras (4.0 \pm 0.1 in 1999-2002 to $3.1 \pm 0.1$ in 2011-2014), while total IEQs and IEQ/kg recipient have remained remarkably stable. Total beta cells and beta cells/kg were higher for IAK (5.3 \pm 0.6 vs. $3.6 \pm 0.2)$ and have increased over the eras $(3.0 \pm 0.3$ to $4.5 \pm 0.4$ ). Endotoxin (both total and $/ \mathrm{kg}$ ) has declined sharply over the eras $(0.5 \pm 0.1$ to $0.1 \pm 0.05)$ as has the Stimulation index (3.6 \pm 0.3 to $2.8 \pm 0.2)$. The eras consist of 19992002, 2003-2006, 2007-2010, 2011-2014 and 2015-2018.

\subsection{Intra-hepatic Portal Vein Islet Transplantation}

The hepatic parenchyma through the portal system of the recipient is the implantation site that is routinely used although other sites are being explored [76]. The final islet-cell product suspended in transplant media containing 70 units heparin/ $\mathrm{kg}$ recipient body weight is loaded into a gravity-fed transfer bag for infusion following percutaneous catheterization of the portal vein [14]. This is a minimally invasive procedure performed under local anesthesia in a radiology suite by an interventional radiologist under ultrasonographic and fluoroscopic guidance [14, 80]. The procedure begins with measurement of portal pressure to ensure absence of portal hypertension. The islets ( $~ 5 \mathrm{~mL}$; up to $10 \mathrm{~mL}$ tissue pellet) are suspended in 200 to $400 \mathrm{~mL}$ transplant media with heparin and human albumin contained in a plastic infusion bag [78]. Briefly, a small (7-French) catheter is inserted into the main portal vein and the islets are dripped slowly through the intravenous line connecting the harvested islet bag with the portal catheter. Both, at the midpoint and at the conclusion of the infusion which typically takes 30 to 45 minutes, the portal pressure is measured. If percutaneous access via the portal vein fails, then the procedure can also be performed under general anesthesia during a limited mini-laparotomy with intravenous delivery through the mesocolonic vein [78] or by recanalization of the obliterated left umbilical vein to enable access to the left portal system. In these instances, a dual-lumen 9 French Broviac-type central-line catheter is advanced into the main portal vein for simultaneous monitoring of portal pressure (through the smaller lumen while islets are infused [14, 81, 82].

Following transplantation, subcutaneous heparin and insulin are administered for at least two weeks to promote islet engraftment [78]. The rationale being that patients receiving peritransplant insulin and heparin infusions are more likely to become insulin independent and have a significantly greater percent reduction in insulin requirement [48]. This could be attributed to protection from the instant blood-mediated inflammatory reaction (IBMIR) combined with islet 
rest and other anti-inflammatory effects $[21,48]$. IBMIR is a thrombotic reaction characterized by the activation of coagulation and complement cascades and by platelet consumption that results in the disruption of islet morphology and function [13]. Heparin may be beneficial due to its ability to reduce inflammation via inhibition of complement activation, reduce the generation of reactive oxygen species and secretion of proinflammatory cytokines, inhibit transcription factor nuclear factor kappa-light-chain-enhancer of activated B cells (NFKB), and limit macrophage migration [2, 48]. The benefits of injecting insulin would include protection of the grafted islets from hyperglycemia, resulting in rest and gain vascular supply $[2,48,83]$. Insulin may also suppress the generation of reactive oxygen species and the binding of transcription factor NFKB [2, 48]. By reducing plasma levels of tissue factor and plasminogen early activator inhibitor-1, insulin may also exert an antithrombotic effect, protecting against IBMIR [48].

\subsection{Intra-portal Vein Infusion-related Complications}

Complications that could arise as a result of intra-portal vein infusion are a transient elevation of transaminase, post-infusion portal vein thrombosis and hepatic infarct [14, 78, 80]. With the optimization of the access technique wherein smaller catheters are used and the puncture tract sealed off, the risk of bleeding has significantly decreased [78, 84, 85]. This in turn allows for a more aggressive use of heparin, which combined with limited tissue pellet volume infused (packed cell volume $<5 \mathrm{~mL}$ ) further reduces the risk of portal vein thrombosis close to zero. Complications arising due to partial portal vein thrombosis are also very rare $[85,86]$. A theoretical increased risk of allosensitization also exists since islet allotransplantation requires islet infusions from 2 to 3 donors. It has been clinically observed that discontinuation of immunosuppression due to graft failure or side effects, results in approximately $70 \%$ of the patients developing donor-specific antibody and high panel-reactive antibody (PRA) (>50\%) [87-89]. However, in the presence of adequate immunosuppression, this risk remains very small even after their fourth and fifth islet infusion [88, 90]. Moreover, the risk of sensitization remains the same as after one islet infusion despite increased number of HLA class I mismatches with each infusion [91]. In fact, exposure to repeat HLA class I mismatch in subsequent islet infusions results in less frequent development of de novo HLA class I antibodies compared with new class I mismatch. Poor graft outcome and increased risk for donor-specific antibodies is associated with $>20 \%$ PRA [78]. Posttransplant monitoring of intraportal islets has proven difficult. Positron emission tomography combined with computed tomography may have the potential to assess the early posttransplant loss of islets [92].

\section{Limitations of Clinical Islet Transplantation and Strategies to Address the Limitations}

Widespread application of clinical islet transplantation is hindered by a shortage of donor pancreata, the harmful side effects associated with chronic immunosuppressive therapy, innate and alloimmune graft rejection, and the recurrence of autoimmunity.

\subsection{Shortage of Donor Pancreata}

Usually, islet transplant recipients require islets from two or more pancreata to regain permanent glycometabolic control, which becomes a problem due to the shortage of donor pancreata. In order for clinical islet transplantation to prove cost effective, and to increase 
availability of islets for transplantation and minimize the risk of donor allosensitization, the best scenario would be to use islets from a single donor similar to whole-pancreas transplantation. While several groups have met with limited success using single-donor islet transplants, routine single-donor islet engraftment success has not been observed universally [2, 51, 57, 93].

Several strategies have been investigated to address the issue of shortage of donor tissue. These include amongst others, obtaining islets from donors after cardiac death (DCD), from partial pancreactomized living donors, as well as from alternate, sustainable sources of islets such as porcine islets. Another avenue that has been explored is the directed differentiation of stem or progenitor cells (e.g. embryonic stem cells) or induced pluripotent stem cells into insulinproducing beta cells [2, 94-96]. Apart from these obvious stem cell choices, others such as mesenchymal stem cells, adipose tissue-derived stem cells, umbilical cord blood-derived stem cells, as well as organ-specific facultative progenitor cells from the liver and the pancreas, have also been tested for their ability to differentiate into bona fide insulin-secreting beta cells. Additionally, the generation of insulin-producing beta cells by transdifferentiation of alpha cells, non-islet pancreatic ductal cells, acinar cells, hepatic cells, and bile duct epithelial cells into insulinproducing beta cells as well as agents such as Exenatide that stimulate regeneration of beta cells have also been studied [2, 94-96].

Apart from the overall shortage of cadaveric donor pancreata, the quality of a donor pancreas also plays an important role in determining transplant outcomes, with factors such as donor age and BMI, cause of death, duration of hospital stay, organ procurement team and cold ischemia time acting as major contributors [97-102]. Currently, the islet transplantation procedure is hindered by the quality of pancreas allocated. For example, donor pancreases unsuitable for whole-pancreas transplantation such as pancreas from older, overweight donors that are associated with decreased survival when utilized in whole-organ pancreas transplant are allocated for islet transplantation [2, 103]. In order to better long-term islet transplantation outcomes, this disparity in organ allocation will definitely need to be addressed.

Another important point is the ischemic, mechanical, and enzymatic stress that islets are subjected to during the isolation process [12]. Efforts to protect islets by either tweaking isolation techniques or by treating the islets are ongoing. Currently many clinical trials are focusing on cytoprotective strategies to enhance transplantation outcomes. Some of these are listed below:

- Phase I/II clinical trial \# NCT02520076 studies the use of Serine protease inhibitor Alpha-1 Antitrypsin (AAT) in islet transplant to decrease the amount of cell death caused by general inflammation and improve single donor success rate in clinical islet transplantation. \#NCT02464878 is another multicenter trial that focuses on the effect of AAT on islet transplant engraftment and durability after renal transplant. In the clinical trial \#NCT02713997, following removal of pancreas from patients with chronic pancreatitis, autoislets are transplanted back into patient's liver along with three inflammatory therapies arms: Tumor necrosis factor (TNF)-alpha, AAT and standard care in order to see if anti-inflammatory therapy improves outcomes after total pancreatectomy with islet autotransplantation (TPIAT).

- In clinical trial \#NCT03073577, the use of supplementing islet preservation medium during islet isolation process with anti-aging glycopeptide (PKX-001) is being studied. Islets are maintained for minimal 6-72 $\mathrm{h}$ in supplemented CMRL1066-based media containing PKX-001 until the time of transplant. 
- Islet Isolation using MnTE-2-PyP (BMX-010) is a phase I pilot study (\#NCT02457858) that has been completed. The investigators hypothesized that addition of antioxidant BMX-010 to perfusion solution, digestion solution and culture medium during the islet isolation process could lead to greater preservation of islet mass and metabolic function, such as improved islet yield, viability and functional potency.

- Clinical trial \# NCT00678990 is a phase I, open study (not yet recruiting) to evaluate safety and efficacy of allogenic islet transplantation using islets coated with immobilized heparin. In this study, prior to transplantation, islets will be surface modified to carry immobilized heparin. The primary objective is to investigate safety and efficacy of islet allotransplantation using islets coated with immobilized heparin. The modification with heparin is anticipated to protect islets from blood (coagulation and inflammation) as a means to preserve a larger portion of the islets in the initial transplant phase.

- The effect of selective complement inhibition using complement inhibitor Eculizumab combined with standard anticoagulation during and after transplantation, in reducing the extent of early tissue loss after portal infusion of islets, has also been studied in completed clinical trial \# NCT02727608.

- The C-X-C Motif Chemokine Ligand 8 (CXCL8) plays a key role in the recruitment and activation of polymorphonuclear neutrophils in post ischemia reperfusion injury after organ transplantation. Reparixin is a low molecular weight blocker of CXCL8 biological activity in clinical development. Reparixin can be used to immunomodulate and control of nonspecific inflammatory events surrounding the early phases of pancreatic islet transplantation. A phase II/III clinical trial (\#NCT01967888) is being conducted to assess whether reparixin leads to improved transplant outcome as measured by the proportion of insulin-independent patients following TPIAT.

- In a terminated clinical trial \#NCT00853944, the effect of Sitagliptin on graft function following islet transplantation was being studied to evaluate whether administration of Sitagliptin to islet transplant recipients could enhance engraftment when administered up to one-year post transplant. The study was terminated due to lack of enrollment.

- Investigator initiated, Phase I/II clinical trial \#NCT01653899 studies Caspase inhibition in islet transplantation. In this study, type 1 diabetic participants receive a 14-day oral treatment of the investigational caspase inhibitor drug IDN-6556 following their first islet transplant.

- Combinatorial cellular immunotherapy approaches are also being investigated in the field of islet autotransplantation. For example, clinical trial \# NCT02384018 is a mesenchymal stem cell and islet co-transplantation study aimed to evaluate safety and tolerability of autologous bonemarrow derived mesenchymal stromal cells (BM-MSCs) in chronic pancreatitis patients who concurrent to receiving autoislets following total pancreatectomy, are also infused with autologous BM-MSCs.

\subsection{Immunosuppression}

In any allogeneic organ transplant, immunosuppression acts as a double-edged sword, preventing or delaying the graft rejection by the host, but simultaneously increasing the risk for infection and cancer [104-106]. Routinely, during both peri- and post-allotransplantation, multiple induction and maintenance immunosuppressive agents are administered to the graft recipient to prevent graft rejection. The most commonly used component of immunosuppression regimens 
are the Calcineurin-Inhibitors (CNIs) Cyclosporine or Tacrolimus. Interestingly, both have been implicated in renal dysfunction and beta cell toxicity [107-110]. Therefore alternative CNI-free immunosuppression methods that prevent rejection while avoiding the toxicity of CNIs have been thoroughly investigated in islet allotransplantation [111, 112]. Following the spectacular results obtained by the Edmonton group using the corticosteroid-free immunosuppressive regimen, more than $90 \%$ of islet programs adopted their protocol [15] i.e Rapamycin-based therapy with low doses of tacrolimus and anti-interleukin-2 receptor (IL2R) antibody (Daclizumab) as induction therapy. This approach was designed to improve the survival and function of islets while protecting the kidney function by minimizing CNIs. Induction with IL2R antagonists only, which comprised about 54\% of all initial infusions in 1999-2002, was subsequently replaced or supplemented with regimens that included T-cell depletion with/without TNF antagonists in about $68 \%$ of new infusions performed by 2011 to 2014 [55]. However, the most successful immunosuppressive regimens involved T-cell depletion induction therapy in the form of Thymoglobulin, anti-CD52 antibody (Alemtuzumab), or anti-CD3 humanized antibody [78].

Another trend that emerged to improve outcomes, tolerability and patient compliance was to replace Sirolimus with Tacrolimus and Mycophenolate Mofetil (MMF) [84]. According to the latest CITR annual report, the maintenance immunosuppression in 1999-2002 consisting predominantly of (65\%) CNI plus mammalian target of rapamycin (mTOR) inhibitors has been increasingly replaced or supplemented throughout the eras by a CNI and Inosine Monophosphate Dehydrogenase (IMPDH)-inhibitor combination [55]. In the most recent era (2015-2018), CNI plus mTOR inhibitors were used in 15\% of new infusions while CNI plus IMPDH inhibitors were used in about 56\% [55]. Table 1-2 list active and completed clinical trials that focus on immunosuppressive approaches aimed at improving graft outcomes. Table 3 lists clinical trials that are actively recruiting. Despite their limitations, these studies confirm that it is possible to achieve singledonor insulin independence without using $\mathrm{CNI}$ and steroids. 
Table 1 IMMUNOSUPPRESSION FOR ISLET TRANSPLANTATION. CLINICAL TRIALS: ACTIVE, NOT RECRUITING.

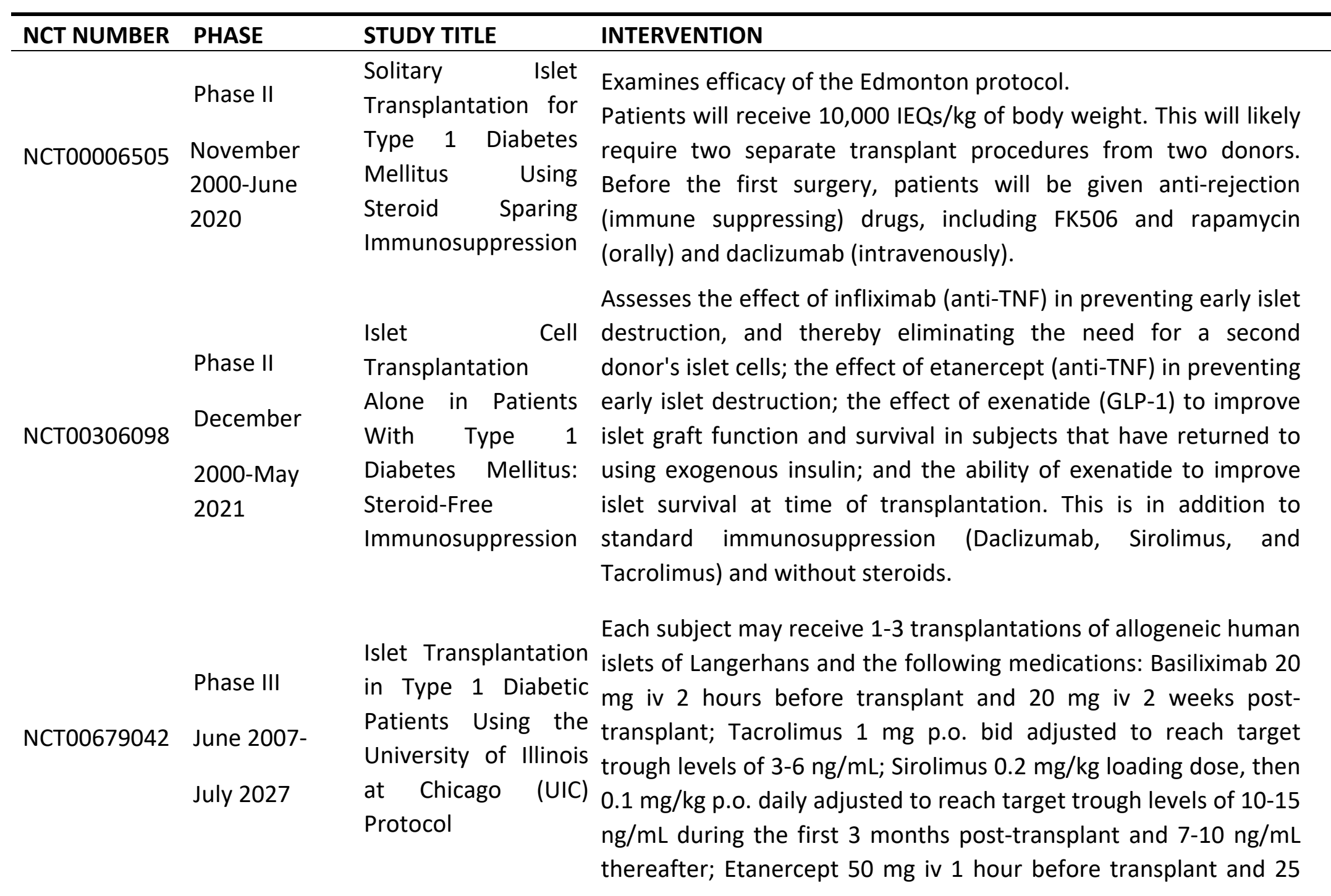

LOCATION

NIH clinical center

Maryland, USA

University of Miami, Diabetes Research Institute, Miami, USA

University of Illinois at Chicago Medical

Center, Illinois, USA 
mg s.c. on days 3, 7 and 10 post-transplant; Exenatide 5-mcg s.c. bid for 1 week, then $10 \mathrm{mcg}$ bid for 6 months after each transplant

Islet

Transplantation

Phase I

NCT00706420 January 2002-

December

2019

Alone (ITA)

Patients

With

Difficult to Control

Type I Diabetes

Mellitus Using a

Glucocorticoid-free

Immunosuppressive

Regimen

Phase III

NCT01897688 June 2012-

A Phase 3 Single

Center Study of Islet

Transplantation in

Non-uremic

March 2027

Diabetic Patients

Phase I and

Phase II

NCT02821026 May 2016-

Omental

Transplant

Sept. 2020

Phase I and

NCT00160732 Phase II

Allogeneic Islet cell transplantation

October
To demonstrate the safety and efficacy of islet transplantation under alemtuzumab induction for treatment of Type-1 Diabetes (T1D) in subjects with hypoglycemia unawareness and a history of severe hypoglycemic episodes.

The new procedure involves transplanting the islets into an Islet omental pouch instead of into the liver. Immunosuppression with anti-thymocyte globulin, tacrolimus, mycophenolic acid, sirolimus and etanercept will be used in this study.

The purpose of this study is to determine the safety of transplanting human islet cells for controlling hyperglycemia in brittle and/or complex patients with type 1 diabetes. The "Edmonton Protocol" of specific anti-rejection drugs without
City of Hope Medical Center

California,

USA

Northwestern

University,

Illinois, USA

Clinical Islet

Transplant

Program, Alberta

Canada

The University of

Chicago Hospitals, Illinois USA 
October2025

Table 2 IMMUNOSUPPRESSION FOR ISLET TRANSPLANTATION. CLINICAL TRIALS: COMPLETED.

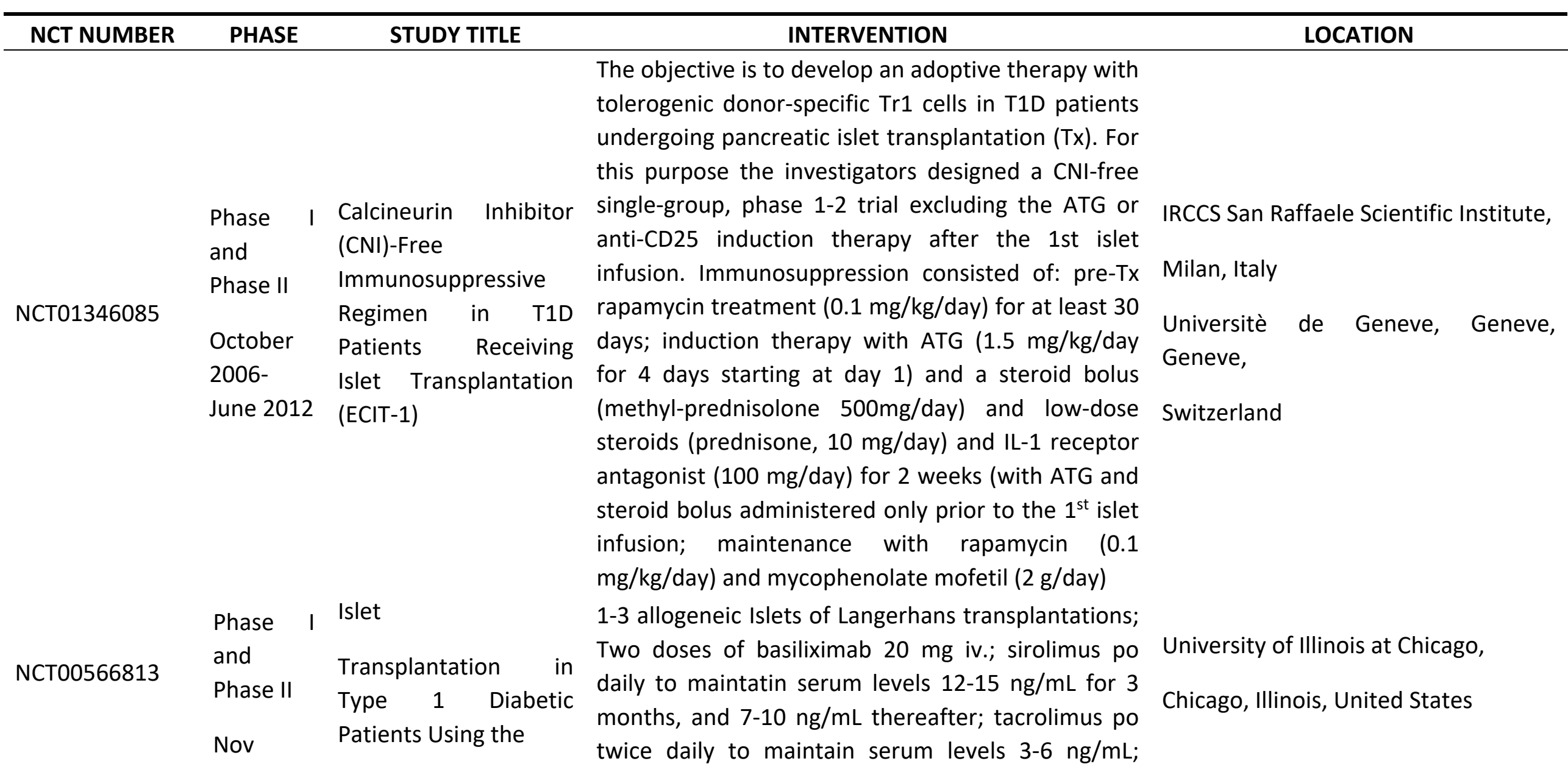


2004- Edmonton Protocol of etanercept $50 \mathrm{mg}$ IV before islet transplant, $25 \mathrm{mg}$ Jan 2007 Steroid Free Immuno- subcutaneously post-transplant days 3, 7, 10 ; suppression

NCT00014911

Phase II

$\begin{array}{ll}\text { Dec Islet Transplantation } \\ \text { 2005- } & \text { Using Abatacept }\end{array}$

Dec 2014

NCT01220856
Phase II exenatide subcutaneously $5 \mathrm{mcg}$ pre-transplant and twice daily for I week, then increased to $10-\mathrm{mcg}$ twice daily for 6 months after the last islet transplant.

This study extends the results obtained from the Edmonton study, which used islet transplantation in Type 1 diabetic patients with steroid-free Reparixin in Pancreatic
Islet Transplantation
Islet Transplantation for Type 1 Diabetes

immunosuppression. In addition to standard Drug: Sirolimus, Tacrolimus and Daclizumab immunosuppression, Sulfamethoxazole, Ganciclovir, Trimethoprim and Pentamidine is given to the patients.

Islet transplantation in type 1 diabetics with hypoglycemic unawareness using abatacept as a part of a novel calcineurin-inhibitor-sparing immunosuppressive regimen. In addition to administered monthly for the duration of functioning islet allografts.

This study is designed to explore the efficacy of reparixin (in concert with standard immunosuppression) in preventing graft dysfunction Efalizumab and Belatacept, Abatacept was
University of Miami, Florida; Massachusetts General Hospital Massachusetts; University of Minnesota, Minnesota; Washington University, Missouri; and Benaroya Research Inst at Virginia Mason Research Center, Washington in USA University of Alberta Alberta in Canada; Justus-Leibig University, Giessen in Germany.University of Milan, Milan in Italy and University of Geneva Geneva, Switzerland.

Emory University, Atlanta, Georgia,

United States

- University Hospital Carl Gustav CarusDresden, Dresden, Germany 


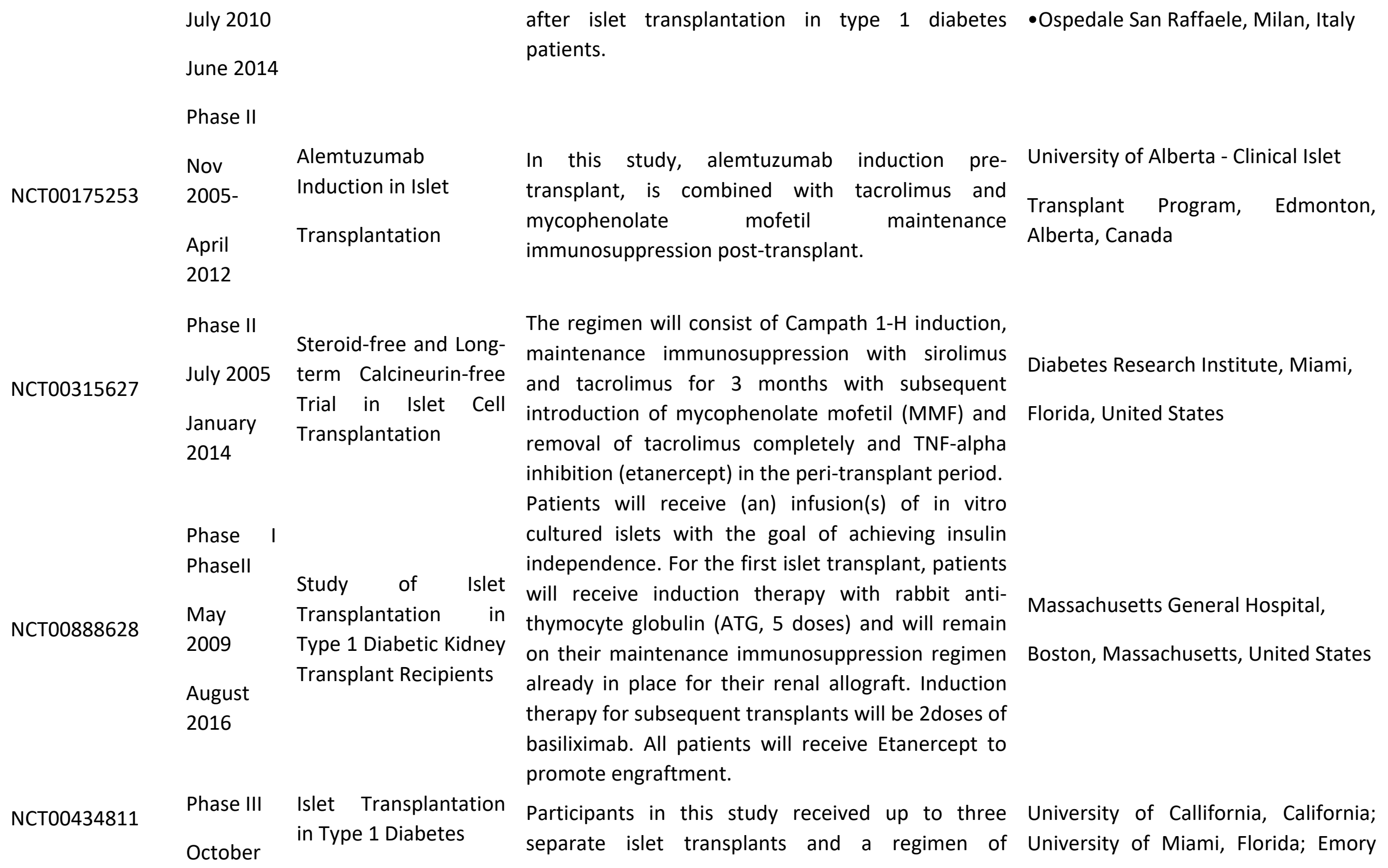


2006

May

2014

NCT00434850

2008

April

2013 immunosuppressive antithymocyte globulin (ATG), sirolimus, and lowdose tacrolimus. Etanercept taken on the day of will be used in place of ATG for the second and third transplants.

Participants in this study received up to three separate islet transplants and a regimen of immunosuppressive medications consisting of belatacept, basiliximab (an IL-2 monoclonal antibody receptor blocker), and mycophenolate mofetil.

\section{LEA29Y (Belatacept)}

October

\section{Phase II Peritransplant}

Deoxyspergualin

Oct 2006Islet transplantation in

Nov 2013 Type 1 Diabetes

The purpose of this study is to assess the safety and efficacy of deoxyspergualin (DSG), an immunosuppressant drug, on post-transplant islet function in people with type 1 diabetes who have not responded to intensive insulin therapy. transplant and thrice post-transplant. Basiliximab

University, Georgia, Northwestern University, Illinois; University of Illinois, Illinois; University of Minnesota, Minnesota; University of Pennsyl-vania, Pennsylvania; in USA; Univer- sity of Alberta, Alberta, Canada.

Emory University, Atlanta, Georgia, United States

University of Alberta, Edmonton, Alberta, Canada

University of Californinia, San Francisco, Participants in this study will receive up to three separate islet transplants. They will also receive ATG, sirolimus, Tacrolimus, and Etanercept.
San Francisco, California, United States

- Northwestern University, Chicago, Illinois, United States

- University of Minnesota, Minneapolis,

Minnesota, United States 


\begin{tabular}{|c|c|c|c|c|}
\hline \multirow[b]{2}{*}{ NCT00285233 } & $\begin{array}{l}\text { Phase I \& } \\
\text { Phase II }\end{array}$ & $\begin{array}{l}\text { Delayed } \\
\text { Mycophenolate }\end{array}$ & \multirow{2}{*}{$\begin{array}{l}\text { The objective of this study was to assess the safety } \\
\text { and efficacy of islet allotransplantation for the } \\
\text { reestablishment of stable glycemic control in } \\
\text { patients with type } 1 \text { diabetes, using anti-thymocyte } \\
\text { globulin induction immunosuppression with } \\
\text { sirolimus, mycophenolate mofetil and low dose } \\
\text { tacrolimus maintenance immunosuppression. }\end{array}$} & \\
\hline & $\begin{array}{l}\text { Sept } \\
2000- \\
\text { March } \\
2005\end{array}$ & $\begin{array}{l}\text { Mofetil in Single- } \\
\text { Donor Islet } \\
\text { Allotransplantation in } \\
\text { Type } 1 \text { Diabetes }\end{array}$ & & $\begin{array}{l}\text { University of Minnesota, Minneapolis, } \\
\text { Minnesota, United States }\end{array}$ \\
\hline & $\begin{array}{l}\text { Phase I \& } \\
\text { Phase II }\end{array}$ & $\begin{array}{lr}\text { hOKT3y1 } & \text { (Ala-Ala) } \\
\text { Combined } & \text { With }\end{array}$ & $\begin{array}{l}\text { This was an open-label, one-year follow-up study of } \\
\text { type } 1 \text { diabetic islet allograft recipients who receive }\end{array}$ & \\
\hline NCT00285194 & $\begin{array}{l}\text { April } \\
2000\end{array}$ & $\begin{array}{l}\text { Sirolimus and Delayed } \\
\text { Tacrolimus in Type } 1 \\
\text { Diabetic Islet Allograft }\end{array}$ & $\begin{array}{l}\text { FcR non-binding OKT3 antibody hOKT3Y1 (Ala-Ala) } \\
\text { plus sirolimus induction immunotherapy combined } \\
\text { with sirolimus and delayed tacrolimus maintenance }\end{array}$ & $\begin{array}{l}\text { Universtiy of Minnesota, Minneapolis, } \\
\text { Minnesota, United States }\end{array}$ \\
\hline & $\begin{array}{l}\text { January } \\
2004\end{array}$ & Recipients & $\begin{array}{l}\text { immunosuppression. Six } \quad \text { subjects } \text { were } \\
\text { transplanted. }\end{array}$ & \\
\hline
\end{tabular}

Table 3 IMMUNOSUPPRESSION FOR ISLET TRANSPLANTATION. CLINICAL TRIALS: RECRUITING.

\begin{tabular}{|c|c|c|c|c|}
\hline NCT NUMBER & PHASE & STUDY TITLE & INTERVENTION & LOCATION \\
\hline NCT01909245 & $\begin{array}{l}\text { Phase II } \\
\text { October } \\
2013 \\
\text { July } 2021\end{array}$ & $\begin{array}{l}\text { Islet Cell Transplant } \\
\text { for Type } 1 \text { Diabetes } \\
\text { (TCD) }\end{array}$ & $\begin{array}{l}\text { The purpose of this study is to determine if islet cell } \\
\text { transplantation using ATG or alemtuzumab, along with additional } \\
\text { medications to prevent the body from rejecting the transplanted } \\
\text { cells, is a safe and effective treatment for type } 1 \text { diabetes. Study } \\
\text { participants may receive up to three islet transplants and will be } \\
\text { followed for five years to monitor blood sugar control, islet } \\
\text { transplant function, and changes in quality of life. }\end{array}$ & $\begin{array}{l}\text { City of Hope } \\
\text { Medical Center, } \\
\text { Duarte, } \\
\text { California, United } \\
\text { States }\end{array}$ \\
\hline NCT03444064 & Phase I & PolyTreg & The primary goal is to assess the safety and feasibility of & University \\
\hline
\end{tabular}


February

2018-

March 2021

May 2012

June 2030

NCT01630850

NCT01241864

Phase II

Dec 2010-
Immunothera

Transplantation

autologous PolyTregs in islet transplant patients.

The control group will receive the current Edmonton islet transplant induction therapy (Alemtuzumab with Etanercept and Anakinra). The intervention group will receive islet transplant with same induction therapy as control group and PolyTregs (400-1600 million) six weeks post- transplant. All participants will be maintained on low dose tacrolimus and sirolimus immunosuppression.

Islet Transplantation The purpose of this study is to learn about the safety of islet in Patients With transplantation for Type 1 diabetes mellitus. Immunosuppression "Brittle" Type I may include remicade, thymoglobulin, prograf, solu-medrol, and Diabetes cellcept. Dosage will vary per patient based on weight.

The purpose of this study is to learn about the safety of islet

Islet Transplantation

in Type 1 Diabetic

Dec 2025

Kidney Allograft $\operatorname{tr}$

Immunosuppression varies but may include prograf, cellcept,

sirolimus, prednisone. Dosage will vary per patient based on weight.
Alberta,

Edmonton,

Alberta, Canada

University of

Chicago Medical

Center,

Chicago, Illinois,

United States

The University of Chicago, Chicago,

Illinois, United

States 
More recently, Salk Institute scientists have generated the first immune-evasive, glucose responsive human islet-like organoids (HILOs) from induced pluripotent stem cells that provide a promising alternative to cadaveric and device-dependent therapies in the treatment of diabetes [113]. They demonstrated that non-canonical WNT4 signaling drives the metabolic maturation of HILOs necessary for robust ex vivo glucose-stimulated insulin secretion. HILOs are able to reestablish glucose homeostasis in diabetic immunodeficient NOD/SCID mice following transplantation. Furthermore, overexpression of programmed death-ligand 1 (PD-L1) promotes the survival of HILO xenograft, restoring glucose homeostasis in Streptozotocin-induced, immunocompetent diabetic mice for 50 days. In vitro stimulation with interferon- $\gamma$ (IFN- $\gamma$ ) induces endogenous PD-L1 expression and restricts T cell activation and graft rejection. Extensive research and preclinical testing to confirm the durability, safety and efficacy of this system for use in humans is still required to advance this system to clinical trials.

\subsection{Graft Function}

Currently, approximately $30-50 \%$ of original islet mass can be recovered from a cadaveric pancreas for transplantation [78]. Of this, approximately half of the transplanted islets are further destroyed by the IBMIR, a serious obstacle to successful islet engraftment. First achievement of insulin independence measured from initial islet infusion with or without subsequent infusion, is an indicator of the rate of engraftment under real-time conditions that include early graft loss, islet resource availability, patient/doctor decisions and myriad other factors [55]. The first islet infusion usually results in partial islet function correlating with detectable serum C-peptide, lowering of insulin requirements in $40-60 \%$ of the recipients, immediate improvement in glucose control with $\mathrm{HbA} 1 \mathrm{c}$ at $<7 \%$ and prevention of severe hypoglycemic episodes and hypoglycemic unawareness, resulting in an instant improvement in quality of life [14, 78, 114]. Using the original Edmonton Protocol, a steep loss of insulin independence was observed by the third year, but in most of the transplanted patients a persistent C-peptide and continuous longitudinal protection from hypoglycemia was observed [43]. Apart from allograft rejection and the recurrence of autoimmunity exacerbated by marginal initial islet mass engraftment, a number of factors played a contributory role in the long-term loss of insulin independence. However since then, advances in donor selection, islet isolation, antirejection and anti-inflammatory agents have yielded clinical islet transplant outcomes that mirror whole-organ pancreas transplantation outcomes, achieving greater than $\sim 70 \%$ and $\sim 50 \%$ insulin independence rates in select centers at one year and five years post-transplantation [14, 16, 17, 45, 47, 56, 94, 115-121]. According to the latest CITR report, it is notable that the cumulative rate of achievement of insulin independence follows the general shape of engraftment curves for solid organs, but with a slower initial slope, indicative of multiple infusions [55]. While the overall rate of first achievement of insulin independence is, remarkably, nearly identical between islet transplantation alone and islet after kidney recipients, the most predictive factors of this endpoint for islet transplantation alone were, immunosuppression with IL2R antagonists and recipient age $\geq 35$. Factors that result in optimized outcomes post last infusion included, induction immunosuppression with $\mathrm{T}$ cell depletion and/or TNF-alpha inhibitor, maintenance immunosuppression with mTOR inhibitor and CNI, IEQ's $\geq 325,000$ [55]. The CITR report also demonstrates that even moderate amounts of endogenous Cpeptide significantly improves $\mathrm{HbA1C}$ which in turn contributes to reducing the risk of long-term 
complications such as those affecting the vasculature and peripheral nerves. Additionally, a complete abolition of severe hypoglycemic episodes and impaired awareness of hypoglycemia is observed in most cases indicating that islet transplantation offers an alternative form of cure for patients who cannot achieve adequate glycemic control using intensive exogenous insulin treatment and suffer from debilitating and recurrent hypoglycemic events [56].

\subsection{Islet/beta Cell Encapsulation Strategies}

Islet encapsulation strategies involve encapsulation of human or pig islets with a semipermeable barrier consisting of a semi-porous device (micro- or macro-encapsulation/bioartificial pancreas) [5]. The device needs to support the exchange of nutrients and oxygen as well as allow the encapsulated islets to sense fluctuations in blood glucose and respond by secreting insulin. It should also physically isolate the islets from the host's immune responses potentially eliminating the requirement for toxic systemic immunosuppression [5, 102]. Despite the progress in biomaterial strategies for encapsulation, the host's immune responses to foreign materials remains a major limitation hindering their potential for clinical transplantation. Clinical trials of porcine islets conducted in New Zealand and Argentina [122-127] have met with limited success, however there is still a considerable amount of work involving optimization of encapsulation methods and materials that needs to be accomplished before the technique can be used in large clinical trials in the US.

Clinical trials that are currently looking into islet encapsulation strategies are listed below:

- ClinicalTrial \# NCT03513939 is a Phase I/II trial that studies the safety, tolerability and efficacy of implanting the Sernova's Cell Pouch ${ }^{\mathrm{TM}}$ subcutaneously. The Cell Pouch $^{\mathrm{TM}}$ is designed as a scaffold made of non-degradable polymers, formed into small cylindrical chambers which, when placed in the subcutaneous site, becomes incorporated with tissue and microvessels to the circumference of removable plugs within as early as two weeks as demonstrated in preclinical studies. After tissue incorporation, the plugs are removed, leaving fully formed tissue chambers with central void spaces for the transplantation of therapeutic cells including islets. The Cell Pouch $^{\mathrm{TM}}$ forms a natural environment, rich in microvessels that allows the transplanted islets to engraft with intravascular microvessels. It is believed that this engraftment will enable long-term survival and function of transplanted islets. Immunosuppression is initiated after a minimum of three weeks after Cell Pouch ${ }^{\mathrm{TM}}$ implantation, and optimized for another three weeks. This allows for proper vascularization of the Cell Pouch $^{\text {TM }}$ chambers and the patient to be stabilized on immunosuppression prior to transplantation. A mass of highly purified islets $(>3,000$ IEQs per kg of patient body weight) can be transplanted in the Cell Pouch ${ }^{\mathrm{TM}}$.

- Clinical trial \# NCT00790257 is a phase I clinical trial to study the safety and efficacy study of encapsulated human islet allotransplantation to treat T1D. With the view to avoid immunosuppression, this protocol tests the safety and the efficacy of encapsulated human islets in a "Monolayer Cellular Device" for islet allotransplantation in type 1 diabetic patients, performed at the University clinical hospital Saint-Luc, Brussels. Encapsulated human islets will be transplanted in the subcutaneous tissue as a "safety procedure" for patients.

- Clinical trial \# NCT01379729 is a phase I clinical trial that studies an alginate embedded human beta cell graft in a "therapeutic" dose in the intraperitoneal cavity of type 1 diabetic patients under immunosuppression with Tacrolimus/MMF. 
- Clinical trial \# NCT02064309 is a phase I/II clinical trial to assess the safety and efficacy of transplantation of macro-encapsulated human islets within the Bioartificial Pancreas Beta-Air implanted subcutaneously in patients with T1D without immunosuppression.

Based on the futuristic prospect that human stem cell derived islets may be used for islet transplantation thereby addressing the limitation of shortage of donor organs to provide islets, California based company ViaCyte Inc. has successfully differentiated human embryonic stem cells ( $h E S C s$ ) into pancreatic endoderm cells (PEC). The PECs displayed positive C-peptide, pro-insulin as well as key transcription factors that led to regulated insulin production post-transplantation and in-vivo differentiation [16, 96-97, 127]. Two clinical trials of Viacyte's VC-01(NCT02239354) and VC-02 (NCT03163511) utilize these hESC-derived PECs encased in a macroencapsulation device and implanted subcutaneously. In the first clinical trial, the encapsulation device has an intact membrane preventing direct immune cell-to-cell contact, whereas in the second trial, the device has microperforations designed to improve neovascularization, but necessitating requisite immunosuppression. Ongoing data are eagerly awaited to validate the safety and preliminary efficacy of these promising approaches.

\subsection{Islet Transplantation in Extrahepatic Sites}

The current site of transplantation in the liver is not ideal, due to several factors. These include amongst others, significant liver inflammation following islet infusion; potential complications such as massive bleeding and thrombosis, portal hypertension and fatal hepatic necrosis; islet toxicity due to high levels of immunosuppressants and gastrointestinal toxins; inability to retrieve islets post-transplantation; and development of graft dysfunction in a number of intrahepatic allogeneic and autologous islet graft recipients [12, 14, 77, 128-131]. Furthermore, islets in the liver, are subjected to variable glucose concentrations than they would be exposed to in the pancreas which could be toxic $[12,131]$. Also compared to the native tissue oxygen tension and parenchymal oxygen tension of 40 and $30 \mathrm{mmHg}$ that islets are exposed to in the pancreas, the liver has significantly lower tensions of $<10 \mathrm{mmHg}$ for both $[12,130,132]$. Free fatty acids are also thought to potentially contribute to islet dysfunction in the liver [133]. Additionally, insulin secretion results in triglyceride deposition into the surrounding hepatic tissue further exacerbating this problem.

Other extrahepatic sites that have been explored include amongst others bone marrow, the gastric submucosa, genitourinary tract, the omentum, anterior eye chamber, testis, thymus, striated muscle, kidney capsule and the peritoneum $[5,12,16,131]$. Of these, sites favored have been the omental pouch due to its high level of angiogenic factors, the brachioradialis muscle where there has been some success, under the kidney capsule, within a venous sac, immune privileged sites which would allow for the avoidance of rejection, and also the pancreas itself although there is insufficient evidence for this location [12].

Several clinical trials are currently recruiting or active, are studying alternative site of transplantation. For instance, Clinical trial \# NCT02213003, NCT02821026 and NCT02803905 study islet allotransplantation in the omentum; Clinical trial \# NCT03977662 studies cotransplantation of allogeneic parathyroid glands (PTG) with adult pancreatic islets in the intramuscular site; Clinical trial \# NCT02916680 studies islet transplantation in the anterior chamber of the eye; Clinical trial \# 
NCT01722682 studies islet transplantation in the bone-marrow; and Clinical trial \# NCT01571817 and NCT02402439 study islet transplantation in the gastric submucosa.

\section{Islet Transplantation: Way Past an Experimental Procedure}

In Australia, Canada and many Asian and European countries including United Kindgdom, Sweden, Switzerland, France and Italy, islet allotransplantation is approved and covered by national healthcare systems [14]. However in the US, islet allotransplantation is still considered an experimental procedure. Two multicentre phase III Biological Licensure Application (BLA)-enabling islet allotransplantation clinical trials have been conducted that were funded by $\mathrm{NIH}$ and coordinated by the CIT Consortium [79, 134]. These Phase III trials represent a pivotal milestone since these and similar studies will help pave the way towards reimbursement for islet allotransplantation through Medicare and Medicaid, which will have major impact on its future as a therapeutic strategy for T1D in the USA. Currently patients with brittle T1D associated recurrent hypoglycemic episodes or marked glycemic lability as well as cardiovascular disease form the basis of consideration for coverage as pancreas transplantation is not feasible because of the risk of major surgery [21, 81]. Also improved outcomes that have been observed in long-term insulin independence with near normalization of $\mathrm{HbA} 1 \mathrm{c}$ in the absence of severe hypoglycemic episodes in select trials, coupled with advances in technical approaches and immunosuppressive therapy as well as the increase in number of clinical islet allotransplantations performed further bolster the chances of BLA approval $[45,50]$. Costs incurred by this technology such as the costs that are charged by the Organ Procurement Organization for a donor pancreas or costs that are incurred for establishing an Federal Drug Administration (FDA) approved GMP islet isolation facility and maintaining a trained islet isolation team, have also proven to be a major deterrent to its wide spread application. Based on the improvement that has been observed in the quality of life and disease management as well as the reduced risk of diabetes associated complications in patients who have had either an autologous islet transplantation following total pancreatectomy or have had islet allotransplantation for treatment of brittle T1D associated with severe hypoglycemic episodes and unawareness and glycemic lability, the high cost associated with this technology should not play a primary role in the decision-making process to consider third party reimbursement, especially since similar costs are incurred by the already accepted pancreas transplantation [135].

\section{Conclusions}

Over the last 16 years, incremental advances have been made in several aspects of islet transplantation including amongst others, optimized donor selection, better preservation of donor pancreas, improvements in islet isolation technique and experience of the centers and personnel, novel beneficial islet culture techniques prior to transplantation and potent immunosuppressive therapy that promote longitudinal islet transplant outcomes. Improved islet graft durability at five years post transplantation now parallels that of whole pancreas grafts in select centers, with the added advantage of islet transplantation being a less invasive procedure that is accompanied with an improvement in the quality of life due to prevention of severe hypoglycemic episodes and unawareness and risk of complications. The main hurdles that currently remain relate to procedural availability, the cost of the technology and most importantly sustainable 
reimbursement. Islet transplantation is still considered an experimental procedure in the USA and recognition by the FDA would lead to third party reimbursement which would help pave the way to make islet transplantation a clinically therapeutic option with wide-spread application.

\section{Author Contributions}

Both authors contributed equally to this work. Dr. Preeti Chhabra contributed to literature survey, writing, editing and proof-reading this article. Dr. Kenneth L. Brayman contributed to writing and editing this article.

\section{Funding}

American Diabetes Association \#1-17-IBS-244.

\section{Competing Interests}

The authors have declared that no competing interests exist.

\section{References}

1. Dean PG, Kukla A, Stegall MD, Kudva YC. Pancreas transplantation. BMJ. 2017; 357: j1321.

2. Chhabra $\mathrm{P}$, Brayman KL. Overcoming barriers in clinical islet transplantation: Current limitations and future prospects. Curr Probl Surg. 2014; 51: 49-86.

3. JDRF type 1 diabetes facts. Available from: https://www.jdrf.org/t1d-resources/about/facts/

4. ADA American Diabetes Association, Statistics about Diabetes. Available from: https://www.diabetes.org/resources/statistics/statistics-about-diabetes

5. Gamble A, Pepper AR, Bruni A, Shapiro AM. The journey of islet cell transplantation and future development. Islets. 2018; 10: 80-94.

6. Seckold R, Fisher E, de Bock M, King BR, Smart CE. The ups and downs of low-carbohydrate diets in the management of Type 1 diabetes: A review of clinical outcomes. Diabet Med. 2019; 36: 326-334.

7. Yeh HC, Brown TT, Maruthur N, Ranasinghe P, Berger Z, Suh YD, et al. Comparative effectiveness and safety of methods of insulin delivery and glucose monitoring for diabetes mellitus: A systematic review and meta-analysis. Ann Intern Med. 2012; 157: 336-347.

8. Stone JY, Haviland N, Bailey TS. Review of a commercially available hybrid closed-loop insulindelivery system in the treatment of Type 1 diabetes. Ther Deliv. 2018; 9: 77-87.

9. Allen N, Gupta A. Current diabetes technology: Striving for the artificial pancreas. Diagnostics. 2019; 9: 31.

10. Saunders A, Messer LH, Forlenza GP. MiniMed 670G hybrid closed loop artificial pancreas system for the treatment of type 1 diabetes mellitus: Overview of its safety and efficacy. Expert Rev Med Devices. 2019; 16: 845-853.

11. Diabetes Control and Complications Trial Research Group. The effect of intensive treatment of diabetes on the development and progression of long-term complications in insulindependent diabetes mellitus. N Engl J Med. 1993; 329: 977-986.

12. Ramesh A, Chhabra P, Brayman KL. Pancreatic islet transplantation in type 1 diabetes mellitus: An update on recent developments. Curr Diabetes Rev. 2013; 9: 294-311. 
13. Chhabra $P$, Brayman KL. Current status of immunomodulatory and cellular therapies in preclinical and clinical islet transplantation. J Transplant. 2011; 2011: 637692.

14. Shapiro AM, Pokrywczynska M, Ricordi C. Clinical pancreatic islet transplantation. Nat Rev Endocrinol. 2017; 13: 268-277.

15. Shapiro AM, Lakey JR, Ryan EA, Korbutt GS, Toth E, Warnock GL, et al. Islet transplantation in seven patients with type 1 diabetes mellitus using a glucocorticoid-free immunosuppressive regimen. N Engl J Med. 2000; 343: 230-238.

16. Pepper AR, Bruni A, Shapiro AM. Clinical islet transplantation: Is the future finally now? Curr Opin Organ Transplant. 2018; 23: 428-439.

17. Jin SM, Kim KW. Is islet transplantation a realistic approach to curing diabetes? Korean J Intern Med. 2017; 32: 62-66.

18. Schuetz C, Markmann JF. Islet cell transplant: Update on current clinical trials. Curr Transplant Rep. 2016; 3: 254-263.

19. Shapiro AM, Ricordi C, Kirk AD, Knechtle SJ, Larsen CP, Madsen JC, et al. Textbook of organ transplantation. Islet cell transplantation procedure \& surgical technique. New Jersey: WileyBlackwell; 2014. p.1314-p.1333.

20. Bellin MD, Barton FB, Heitman A, Harmon JV, Kandaswamy R, Balamurugan AN, et al. Potent induction immunotherapy promotes long-term insulin independence after islet transplantation in type 1 diabetes. Am J Transplant. 2012; 12: 1576-1583.

21. McCall M, Shapiro AM. Update on islet transplantation. Cold Spring Harb Perspect Med. 2012; 2: a007823.

22. Shapiro AM. State of the art of clinical islet transplantation and novel protocols of immunosuppression. Curr Diab Rep. 2011; 11: 345-354.

23. Banting FG, Best $\mathrm{CH}$, Collip JB, Campbell WR, Fletcher AA. Pancreatic extracts in the treatment of diabetes mellitus. Can Med Assoc J. 1922; 12: 141-146.

24. Minkowski O. Weitere mittheilungen über den diabetes mellitus nach exstirpation des pankreas. Berl Klin Wochenschr. 1892; 29: 90-94.

25. Williams P. Notes on diabetes treated with extract and by grafts of sheep's pancreas. Br Med J. 1894; 2: 1303-1304.

26. Pybus F. Notes on supra renal and pancreatic grafting. Lancet. 1924; 204: 550-551.

27. Ssobolew LW. Zur normalen und pathologischen morphologie der inneren secretion der bauchspeicheldrüse. Die eseutung der Langerhans schen inseln. Virchows Arch. 1902; 168: 91128.

28. Moskalewski S. Isolation and culture of the islets of langerhans of the guinea pig. Gen Comp Endocrinol. 1965; 5: 342-353.

29. Lacy PE, Kostianovsky M. Method for the Isolation of intact islets of Langerhans from the rat pancreas. Diabetes. 1967; 16: 35-39.

30. Ballinger WF, Lacy PE. Transplantation of intact pancreatic islets in rats. Surgery. 1972; 72 : 175-186.

31. Kemp CB, Knight MJ, Scharp DW, Lacy PE, Ballinger WF. Transplantation of isolated pancreatic islets into the portal vein of diabetic rats. Nature. 1973; 244: 447.

32. Payne WD, Sutherland DE, Matas AJ, Najarian JS. Amelioration of diabetes in rats by transplantation of islet tissue from a single donor to multiple recipients. Surg Forum. 1977; 28: 301-304. 
33. Najarian JS, Sutherland DE, Matas AJ, Goetz FC. Human islet autotransplantation following pancreatectomy. Transplant Proc. 1979; 11: 336-340.

34. Najarian JS, Sutherland DE, Baumgartner D, Burke B, Rynasiewicz JJ, Matas AJ, et al. Total or near total pancreatectomy and islet autotransplantation for treatment of chronic pancreatitis. Ann Surg. 1980; 192: 526-542.

35. Ricordi C, Lacy PE, Finke EH, Olack BJ, Scharp DW. Automated method for isolation of human pancreatic islets. Diabetes. 1988; 37: 413-420.

36. Piemonti L, Pileggi A. 25 years of the ricordi automated method for islet isolation. CellR4 Repair Replace Regen Reprogram. 2013; 1: e128.

37. Tzakis AG, Zeng Y, Fung JJ, Todo S, Demetris AJ, Starzl TE, et al. Pancreatic islet transplantation after upper abdominal exenteration and liver replacement. Lancet. 1990; 336: 402-405.

38. Ricordi C, Tzakis AG, Carroll PB, Zeng YJ, Rilo HL, Alejandro R, et al. Human islet isolation and allotransplantation in 22 consecutive cases. Transplantation. 1992; 53: 407-414.

39. Hering BJ, Bretzel RG, Hopt UT, Brandhorst H, Brandhorst D, Bollen CC, et al. New protocol toward prevention of early human islet allograft failure. Transplant Proc. 1994; 26: 570-571.

40. Bretzel RG, Brandhorst D, Brandhorst H, Eckhard M, Ernst W, Friemann S, et al. Improved survival of intraportal pancreatic islet cell allografts in patients with type 1 diabetes mellitus by refined peritransplant management. J Mol Med. 1999; 77: 140-143.

41. Alejandro R, Angelico MC, Ricordi C, Burke G, Nery J, Miller J, et al. Long-term function of islet allograft in type I diabetes mellitus. Transplant Proc. 1995; 27: 3158.

42. Merani S, Shapiro AM. Current status of pancreatic islet transplantation. Clin Sci. 2006; 110: 611-625.

43. Ryan EA, Paty BW, Senior PA, Bigam D, Alfadhli E, Kneteman NM, et al. Five-year follow-up after clinical islet transplantation. Diabetes. 2005; 54: 2060-2069.

44. Shapiro AM, Ricordi C, Hering BJ, Auchincloss H, Lindblad R, Robertson RP, et al. International trial of the Edmonton protocol for islet transplantation. New Engl J Med. 2006; 355: 13181330.

45. Bellin MD, Barton FB, Heitman A, Harmon JV, Kandaswamy R, Balamurugan AN, et al. Potent induction immunotherapy promotes long-term insulin independence after islet transplantation in type 1 diabetes. Am J Transplant. 2012; 12: 1576-1583.

46. Vantyghem MC, Kerr-Conte J, Arnalsteen L, Sergent G, Defrance F, Gmyr V, et al. Primary graft function, metabolic control, and graft survival after islet transplantation. Diabetes Care. 2009; 32: 1473-1478.

47. Bellin MD, Kandaswamy R, Parkey J, Zhang HJ, Liu B, Ihm SH, et al. Prolonged insulin independence after islet allotransplants in recipients with type 1 diabetes. Am J Transplant. 2008; 8: 2463-2470.

48. Koh A, Senior P, Salam A, Kin T, Imes S, Dinyari $P$, et al. Insulin-heparin infusions peritransplant substantially improve single-donor clinical islet transplant success. Transplantation. 2010; 89: 465-471.

49. Leitão $C B$, Tharavanij $T$, Cure $P$, Pileggi A, Baidal DA, Ricordi $C$, et al. Restoration of hypoglycemia awareness after islet transplantation. Diabetes Care. 2008; 31: 2113-2115.

50. Berney T, Ferrari-Lacraz S, Bühler L, Oberholzer J, Marangon N, Philippe J, et al. Long-term insulin-independence after allogeneic islet transplantation for type 1 diabetes: Over the10year mark. Am J Transplant. 2009; 9: 419-423. 
51. Shapiro AM. Strategies toward single-donor islets of Langerhans transplantation. Curr Opin OrganTransplant. 2011; 16: 627-631.

52. Mineo D, Pileggi A, Alejandro R, Ricordi C. Point: Steady progress and current challenges in clinical islet transplantation. Diabetes Care. 2009; 32: 1563-1569.

53. Barton FB, Rickels MR, Alejandro R, Hering BJ, Wease $S$, Naziruddin B, et al. Improvement in outcomes of clinical islet transplantation:1999-2010. Diabetes Care. 2012; 35: 1436-1445.

54. Jamiolkowski RM, Guo LY, Li YR, Shaffer SM, Naji A. Islet transplantation in type I diabetes mellitus. Yale J Biol Med. 2012; 85: 37-43.

55. Collaborative Islet Transplant Registry. CITR 10th annual report. Avaliable from: https://www.citregistry.org/content/citr-10th-annual-report

56. Othonos N, Choudhary P. Who should be considered for islet transplantation alone? Curr Diab Rep. 2017; 17: 23.

57. Tatum JA, Meneveau MO, Brayman KL. Single-donor islet transplantation in type 1 diabetes: Patient selection and special considerations. Diabetes Metab Syndr Obes. 2017; 10: 73-78.

58. Manrique A, Jiménez C, Herrero ML, Meneu JC, Abradelo M, Moreno A, et al. Pancreas preservation with the University of Wisconsin versus Celsior solutions. Transplant Proc. 2006; 38: 2582-2584.

59. Iwanaga Y, Sutherland DE, Harmon JV, Papas KK. Pancreas preservation for pancreas and islet transplantation. Curr Opin Organ Transplant. 2008; 13: 135-141.

60. Hubert T, Gmyr V, Arnalsteen L, Jany T, Triponez F, Caiazzo R, et al. Influence of preservation solution on human islet isolation outcome. Transplantation. 2007; 83: 270-276.

61. Giraud S, Claire B, Eugene M, Debre P, Richard F, Barrou B. A new preservation solution increases islet yield and reduces graft immunogenicity in pancreatic islet transplantation. Transplantation. 2007; 83: 1397-1400.

62. Sthle $M$, Foss A, Gustafsson B, Lempinen $M$, Lundgren $T$, Rafael $E$, et al. Evaluation of perfluorohexyloctane/polydimethylsiloxane for pancreas preservation for clinical islet isolation and transplantation. Cell Transplant. 2016; 25: 2269-2276.

63. Hering BJ, Matsumoto I, Sawada T, Nakano M, Sakai T, Kandaswamy R, et al. Impact of twolayer pancreas preservation on islet isolation and transplantation. Transplantation. 2002; 74: 1813-1816.

64. Fraker CA, Alejandro R, Ricordi C. Use of oxygenated perfluorocarbon toward making every pancreas count. Transplantation. 2002; 74: 1811-1812.

65. Tsujimura T, Kuroda Y, Kin T, Avila JG, Rajotte RV, Korbutt GS, et al. Human islet transplantation from pancreases with prolonged cold ischemia using additional preservation by the two-layer (UW solution/perfluorochemical) cold-storage method. Transplantation. 2002; 74: 1687-1691.

66. Lakey JR, Tsujimura T, Shapiro AM, Kuroda Y. Preservation of the human pancreas before islet isolation using a two-layer (UW solution-perfluorochemical) cold storage method. Transplantation. 2002; 74: 1809-1811.

67. Kin T, Mirbolooki M, Salehi P, Tsukada M, O'Gorman D, Imes S, et al. Islet isolation and transplantation outcomes of pancreas preserved with University of Wisconsin solution versus two-layer method using preoxygenated perfluorocarbon. Transplantation. 2006; 82: 12861290. 
68. Caballero-Corbalán J, Eich T, Lundgren T, Foss A, Felldin M, Källen R, et al. No beneficial effect of two-layer storage compared with UW-storage on human islet isolation and transplantation. Transplantation. 2007; 84: 864-869.

69. Collaborative Islet Transplant Registry (CITR) Annual Report. Rockville, MD: The EMMES Corporation; 2007.

70. Brandhorst H, Friberg A, Nilsson B, Andersson HH, Felldin M, Foss A, et al. Large-scale comparison of liberase $\mathrm{HI}$ and collagenase NB1 utilized for human islet isolation. Cell Transplant. 2010; 19: 3-8.

71. Misawa R, Ricordi C, Miki A, Barker S, Molano RD, Khan A, et al. Evaluation of viable beta-cell mass is useful for selecting collagenase for human islet isolation: Comparison of collagenase NB1 and liberase HI. Cell Transplant. 2012; 21: 39-47.

72. Balamurugan AN, Breite AG, Anazawa T, Loganathan G, Wilhelm JJ, Papas KK, et al. Successful human islet isolation and transplantation indicating the importance of class 1 collagenase and collagen degradation activity assay. Transplantation. 2010; 89: 954-961.

73. Qi M, Valiente L, McFadden B, Omori K, Bilbao S, Juan J, et al. The choice of enzyme for human pancreas digestion is a critical factor for increasing the success of islet isolation. Transplant Direct. 2015; 1: e14.

74. Ionescu-Tirgoviste C, Gagniuc PA, Gubceac E, Mardare L, Popescu I, Dima S, et al. A 3D map of the islet routes throughout the healthy human pancreas. Sci Rep. 2015; 5: 14634.

75. Nano R, Clissi B, Melzi R, Calori G, Maffi P, Antonioli B, et al. Islet isolation for allotransplantation: Variables associated with successful islet yield and graft function. Diabetologia. 2005; 48: 906-912.

76. Piemonti L. Islet Transplantation. 2019 Jul 21. Endotext [Internet]. South Dartmouth, MA: MDText.com, Inc.; 2000-. Available from: https://www.ncbi.nlm.nih.gov/books/NBK278966/

77. Anazawa T, Okajima $\mathrm{H}$, Masui T, Uemoto $\mathrm{S}$. Current state and future evolution of pancreatic islet transplantation. Ann Gastroenterol Surg. 2018; 3: 34-42.

78. Witkowski P, Solomina J, Michael Millis J. Pancreas, biliary tract, liver and spleen. Shackelford's surgery of the alimentary tract, 2 Volume Set. 8th ed. Amsterdam: Elsevier; 2019; 1226-1238.

79. Sever CE, Demetris AJ, Zeng J, Carroll P, Tzakis A, Fung JJ, et al. Composition of human islet cell preparations for transplantation. Acta Diabetol. 1992; 28: 233-238.

80. Agarwal A, Brayman KL. Update on islet cell transplantation for type 1 diabetes. Semin Intervent Radiol. 2012; 29: 90-98.

81. Hering BJ, Clarke WR, Bridges ND, Eggerman TL, Alejandro R, Bellin MD, et al. Phase 3 trial of transplantation of human islets in type 1 diabetes complicated by severe hypoglycemia. Diabetes Care. 2016; 39: 1230-1240.

82. Owen RJ, Ryan EA, O'Kelly K, Lakey JR, McCarthy MC, Paty BW, et al. Percutaneous transhepatic pancreatic islet cell transplantation in type 1 diabetes mellitus: Radiologic aspects. Radiology. 2003; 229: 165-170.

83. Kikawa K, Sakano D, Shiraki N, Tsuyama T, Kume K, Endo F, et al. Beneficial effect of insulin treatment on islet transplantation outcomes in Akita mice. PLoS One. 2014; 9: e95451.

84. Senior PA, Kin T, Shapiro J, Koh A. Islet transplantation at the University of Alberta: Status update and review of progress over the last decade. Can J Diabetes. 2012; 36: 32-37. 
85. Villiger P, Ryan EA, Owen R, O'Kelly K, Oberholzer J, Al Saif F, et al. Prevention of bleeding after islet transplantation: Lessons learned from a multivariate analysis of 132 cases at a single institution. Am J Transplant. 2005; 5: 2992-2998.

86. Kawahara T, Kin T, Kashkoush S, Gala-Lopez B, Bigam DL, Kneteman NM, Koh A, et al. Portal vein thrombosis is a potentially preventable complication in clinical islet transplantation. Am J Transplant. 2011; 11: 2700-2707.

87. Rickels MR, Kearns J, Markmann E, Palanjian M, Markmann JF, Naji A, et al. HLA sensitization in islet transplantation. Clin Transpl. 2006; 413-420.

88. Cardani R, Pileggi A, Ricordi C, Gomez C, Baidal DA, Ponte GG, et al. Allosensitization of islet allograft recipients. Transplantation. 2007; 84: 1413-1427.

89. Campbell PM, Senior PA, Salam A, Labranche K, Bigam DL, Kneteman NM, et al. High risk of sensitization after failed islet transplantation. Am J Transplant. 2007; 7: 2311-2317.

90. Koh A, Imes S, Kin T, Dinyari P, Malcolm A, Toso C, et al. Supplemental islet infusions restore insulin independence after graft dysfunction in islet transplant recipients. Transplantation. 2010; 89: 361-365.

91. Naziruddin B, Wease S, Stablein D, Barton FB, Berney T, Rickels MR, et al. HLA class I sensitization in islet transplant recipients: Report from the Collaborative Islet Transplant Registry. Cell Transplant. 2012; 21: 901-908.

92. Eriksson O, Selvaraju R, Eich T, Willny M, Brismar TB, Carlbom L, et al. Positron emission tomography to assess the outcome of intraportal islet transplantation. Diabetes. 2016; 65: 2482-2489.

93. Hering BJ, Kandaswamy R, Ansite JD, Eckman PM, Nakano M, Sawada T, et al. Single-donor, marginal-dose islet transplantation in patients with type 1 diabetes. JAMA. 2005; 293: 830835.

94. Chhabra P, Brayman KL. Stem cell therapy to cure type 1 diabetes: From hype to hope. Stem Cells Transl Med. 2013; 2: 328-336.

95. Chhabra $\mathrm{P}$, Brayman KL. Stem cell strategies to promote islet transplantation outcomes. OBM Transplant. 2018; 2: 10.

96. Chhabra P, Brayman KL. Contemporary assessment of stem cell therapies for type 1 diabetes mellitus-time for optimism. Encyclopedia of tissue engineering and regenerative medicine. Ocford: Academic Press; 2019. p.189-p.195.

97. Franz C, Görtz M, Wührl M, Kulu Y, Hoffmann K, Hackert T, et al. The role of pre-procurement pancreas suitability score (P-PASS) and pancreas donor risk index (PDRI) in the outcome of simultaneous pancreas and kidney or pancreas after kidney transplantation. Ann Transplant. 2019; 24: 439-445.

98. Wang LJ, Kin T, O'Gorman D, Shapiro AM, Naziruddin B, Takita M, et al. A multicenter study: North American islet donor score in donor pancreas selection for human islet isolation for transplantation. Cell Transplant. 2016; 25: 1515-1523.

99. Fridell JA, Rogers J, Stratta RJ. The pancreas allograft donor: Current status, controversies, and challenges for the future. Clin Transplant. 2010; 24: 433-449.

100. Fridell JA, Stratta RJ. Expanding the pancreas donor pool. Curr Transpl Rep. 2014; 1: 100-112.

101.Lakey JR, Warnock GL, Rajotte RV, Suarez-Alamazor ME, Ao Z, Shapiro AM, et al. Variables in organ donors that affect the recovery of human islets of Langerhans. Transplantation. 1996; 61: 1047-1053. 
102. Chang CA, Lawrence MC, Naziruddin B. Current issues in allogeneic islet transplantation. Curr Opin Organ Transplant. 2017; 22: 437-443.

103. Berney T, Johnson PR. Donor pancreata: Evolving approaches to organ allocation for whole pancreas versus islet transplantation. Transplantation. 2010; 90: 238-243.

104. Fishman JA. Infection in organ transplantation. Am J Transplant. 2017; 17: 856-879.

105. Kuschal C, Thoms KM, Schubert S, Schäfer A, Boeckmann L, Schön MP, et al. Skin cancer in organ transplant recipients: Effects of immunosuppressive medications on DNA repair. Exp Dermatol. 2012; 21: 2-6.

106. Ojo AO, Held PJ, Port FK, Wolfe RA, Leichtman AB, Young EW, et al. Chronic renal failure after transplantation of a nonrenal organ. N Engl J Med. 2003; 349: 931-940.

107.Azzi JR, Sayegh MH, Mallat SG. Calcineurin inhibitors: 40 years later, can't live without.... J Immunol. 2013; 191: 5785-5791.

108. Bechstein WO. Neurotoxicity of calcineurin inhibitors: Impact and clinical management. Transpl Int. 2000; 13: 313-326.

109. Randhawa PS, Starzl TE, Demetris AJ. Tacrolimus (FK506)-associated renal pathology. Adv Anat Pathol. 1997; 4: 265-276.

110. Rangel EB. Tacrolimus in pancreas transplant: A focus on toxicity, diabetogenic effect and drug-drug interactions. Expert Opin Drug Metab Toxicol. 2014; 10: 1585-1605.

111.Ekberg H, Bernasconi C, Tedesco-Silva H, Vitko S, Hugo C, Demirbas A, et al. Calcineurin inhibitor minimization in the Symphony study: Observational results 3 years after transplantation. Am J Transplant. 2009; 9: 1876-1885.

112. Webber $A B$, Vincenti $F$. An update on calcineurin inhibitor-free regimens: The need persists, but the landscape has changed. Transplantation. 2016; 100: 836-843.

113. Yoshihara E, O'Connor C, Gasser E, Wei Z, Oh TG, Tseng TW, et al. Immune-evasive human islet-like organoids ameliorate diabetes. Nature. 2020; 586: 606-611.

114.Rickels MR, Fuller C, Dalton-Baker C, Markmann E, Palanjian M, Cullison K, et al. Restoration of glucose counterregulation by islet transplantation in long-standing type I diabetes. Diabetes. 2015; 64: 1713-1718.

115.Vantyghem MC, Defrance F, Quintin D, Leroy C, Raverdi V, Prévost G, et al. Treating diabetes with islet transplantation: Lessons from the past decade in Lille. Diabetes Metab. 2014; 40: 108-119.

116. Hering BJ. Achieving and maintaining insulin independence in human islet transplant recipients. Transplantation. 2005; 79: 1296-1297.

117. Gibly RF, Graham JG, Luo X, Lowe Jr WL, Hering BJ, Shea LD. Advancing islet transplantation: From engraftment to the immune response. Diabetologia. 2011; 54: 2494-2505.

118.Senior PA, Kin T, Shapiro J, Koh A. Islet transplantation at the University of Alberta: Status update and review of progress over the last decade. Canad J Diabetes. 2012; 36: 32-37.

119. Posselt AM, Szot GL, Frassetto LA, Masharani U, Tavakol M, Amin R, et al. Islet transplantation in type 1 diabetic patients using calcineurin inhibitor-free immunosuppressive protocols based on T-cell adhesion or costimulation blockade. Transplantation. 2010; 90: 1595-1601.

120.Gangemi A, Salehi P, Hatipoglu B, Martellotto J, Barbaro B, Kuechle JB, et al. Islet transplantation for brittle type 1 diabetes: The UIC protocol. Am J Transplant. 2008; 8: 12501261. 
121. Maffi P, Scavini M, Socci C, Piemonti L, Caldara R, Gremizzi C, et al. Risks and benefits of transplantation in the cure of type 1 diabetes: Whole pancreas versus islet transplantation. $A$ single center study. Rev Diabet Stud. 2011; 8: 44-50.

122. Elliott RB, Escobar L, Tan PU, Muzina M, Zwain S, Buchanan C. Live encapsulated porcine islets from a type 1 diabetic patient 9.5 years after xenotransplantation. Xenotransplantation. 2007; 14: 157-161.

123. Wynyard S, Nathu D, Garkavenko O, Denner J, Elliott R. Microbiological safety of the first clinical pig islet xenotransplantation trial in New Zealand. Xenotransplantation. 2014; 21: 309323.

124. Morozov VA, Wynyard S, Matsumoto S, Abalovich A, Denner J, Elliott R. No PERV transmission during a clinical trial of pig islet cell transplantation. Virus Res. 2017; 227: 34-40.

125. Matsumoto S, Abalovich A, Wechsler C, Wynyard S, Elliott RB. Clinical benefit of islet xenotrans-plantation for the treatment of type 1 diabetes. EBioMedicine. 2016; 12: 255-262.

126. Matsumoto S, Tan P, Baker J, Durbin K, Tomiya M, Azuma K, et al. Clinical porcine islet xenotransplantation under comprehensive regulation. Transplant Proc. 2014; 46: 1992-1995.

127.Lilly MA, Davis MF, Fabie JE, Terhune EB, Gallicano GI. Current stem cell based therapies in diabetes. Am J Stem Cells. 2016; 5: 87-98.

128. Chhabra P, Kensinger CD, Moore DJ, Brayman KL. Present accomplishments and future prospects of cell-based therapies for type 1 diabetes mellitus. Type 1 diabetes-pathogenesis, genetics and immunotherapy. London: IntechOpen; 2019. p.295-p.336.

129. Delaune V, Berney T, Lacotte S, Toso C. Intraportal islet transplantation: The impact of the liver microenvironment. Transpl Int. 2017; 30: 227-238.

130. Addison P, Fatakhova K, Rodriguez Rilo HL. Considerations for an alternative site of islet cell transplantation. J Diabetes Sci Technol. 2019; 14: 338-344.

131.Cantarelli E, Piemonti L. Alternative transplantation sites for pancreatic islet grafts. Curr Diab Rep. 2011; 11: 364-374.

132. Piemonti L, Guidotti LG, Battaglia M. Modulation of early inflammatory reactions to promote engraftment and function of transplanted pancreatic islets in autoimmune diabetes. Adv Exp Med Biol. 2010; 654: 725-747.

133. Leitao CB, Bernetti K, Tharavanij T, Cure P, Lauriola V, Berggren PO, et al. Lipotoxicity and decreased islet graft survival. Diabetes Care. 2010; 33: 658-660.

134.US National Library of Medicine, ClinicalTrials. gov. Efficacy of islet after kidney transplantation. Available from: https://clinicaltrials.gov/ct2/show/NCT00468117

135. Bottino R, Knoll MF, Knoll CA, Bertera S, Trucco MM. The future of islet transplantation is now. Front Med. 2018; 5: 202. 


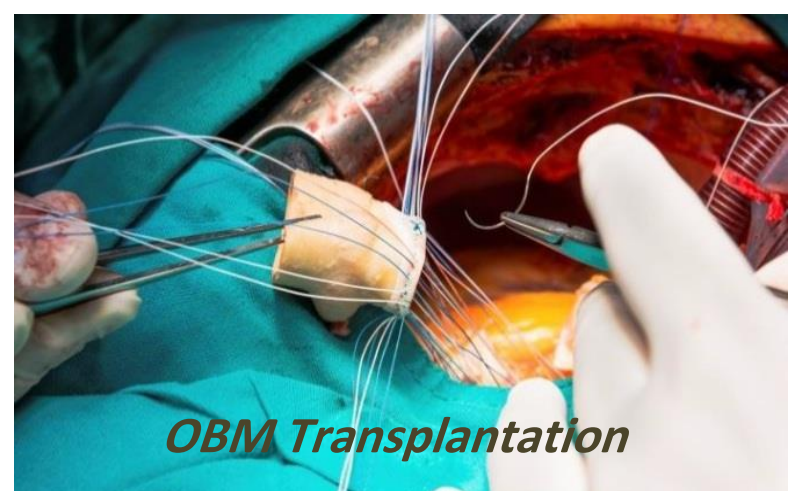

Enjoy OBM Transplantation by:

1. Submitting a manuscript

2. Joining in volunteer reviewer bank

3. Joining Editorial Board

4. Guest editing a special issue

For more details, please visit:

http://www.lidsen.com/journals/transplantation 